\title{
Differences in protein and energy metabolism following portal versus systemic administration of insulin in diabetic dogs
}

Received: 4 May 2005 / Accepted: 22 August 2005 / Published online: 31 January 2006

(C) Springer-Verlag 2006

\begin{abstract}
Aims/hypothesis: In non-diabetic people, insulin levels in the liver are two-fold higher than those in the systemic circulation. In contrast, patients with type 1 diabetes have similar hepatic and systemic insulin levels because insulin is administered peripherally. The aim of this study was to compare the effects of systemic (SI) and preportal (PI) insulin administration on energy, glucose and protein metabolism in chronic insulin-dependent ketosisprone diabetic dogs. Materials and methods: We applied glucose-controlled insulin infusion, indirect calorimetry and stable isotope and radioisotope techniques to measure energy, protein and glucose metabolism. We maintained near-normoglycaemia at identical levels under both study conditions for $20 \mathrm{~h}$. Results: SI was associated with lower oxygen consumption $(130 \pm 13$ vs $161 \pm 8 \mathrm{ml} / \mathrm{min}), \mathrm{CO}_{2}$ production $(99 \pm 10$ vs $130 \pm 8 \mathrm{ml} / \mathrm{min})$, respiratory quotient $(0.76 \pm 0.02$ vs $0.81 \pm 0.01)$ and energy expenditure $(870 \pm 90$ vs $1089 \pm 60 \mathrm{kcal} / 24 \mathrm{~h})(p<0.05$ for all differences $)$. PI increased the respiratory quotient from the insulin-deprived state, whereas SI did not. Glucose kinetics were similar for SI and PI, whereas leucine oxidation ( $36 \pm 4$ vs $54 \pm 5 \mu \mathrm{mol}$ $\mathrm{kg}^{-1} \mathrm{~min}^{-1}$ ) and the fractional synthesis rates of liver tissue protein $(0.68 \pm 0.6$ vs $0.83 \pm 0.07 \% / \mathrm{h})$, albumin $(0.55 \pm 0.06$ vs $0.68 \pm 0.4 \% / \mathrm{h})$, and fibrinogen $(1.73 \pm 0.23$ vs $2.59 \pm$ $0.25 \% / \mathrm{h})$ were all lower during SI than PI $(p<0.05)$. Conclusions/interpretation: The route of insulin administration did not alter glucose metabolism but did affect protein synthesis in the liver. The potential impact of this altered liver protein metabolism on chronic complications needs careful evaluation. A similar decrease in energy expenditure resulting from systemic insulin administration during tight glycaemic control is a potential cause of weight gain.
\end{abstract}

E.-J. Freyse · U. Fischer · S. Knospe

'Gerhardt Katsch' Institute of Diabetes,

17495, Karlsburg, Germany

G. C. Ford · K. S. Nair $(\bowtie)$

Division of Endocrinology and Metabolism, Mayo Clinic,

Rochester, MN 55905, USA

e-mail: nair.sree@mayo.edu

Tel: $+1-507-2552415$

Fax: +1-507-2554828
Keywords Diabetes mellitus · Dog · Energy expenditure · Portal insulin administration · Protein metabolism

Abbreviations FSR: fractional synthesis rates . GCII: glucose-controlled insulin infusion - IW: insulin withdrawal - KIC: ketoisocaproate - MCR: metabolic clearance rates - NOLD: non-oxidative leucine disappearance rate - PI: pre-portal insulin - SI: systemic insulin $\cdot \dot{V} \mathrm{CO}_{2}$ : rate of $\mathrm{CO}_{2}$ production .

$\dot{V} \mathrm{O}_{2}$ : rate of $\mathrm{O}_{2}$ production

\section{Introduction}

Intensive insulin treatment by means of multiple daily injection or continuous subcutaneous infusion by pump is now routinely used to treat patients with type 1 diabetes. These approaches substantially improve glycaemic control and reduce microvascular complications in type 1 and type 2 diabetes $[1,2]$ but may result in variable amounts of weight gain $[3,4]$ and increased hypoglycaemic episodes [5]. Improvement of $\mathrm{HbAlc}$ from $12.9 \pm 0.9 \%$ to $9.6 \pm 0.6 \%$ resulted in $2.4 \pm 0.8 \mathrm{~kg}$ weight gain $(p<0.05)$ after 2 months of intensive insulin therapy in patients with type 1 diabetes [3]. Even with perfect glycaemic control, the employed peripheral route of insulin administration is different from normal physiology in that there is no first-pass hepatic insulin catabolism which normally results in steady-state systemic insulin concentrations being only half that in the portal circulation [6]. The question remains to be answered whether systemic vs portal administration of insulin has any differential impact on metabolic control in diabetes, and whether the possible drawbacks mentioned above of rigorous insulin treatment may be related to the systemic route of insulin administration.

Previous studies have demonstrated that peripheral administration of insulin reduces resting metabolic rate in those with type 1 diabetes $[7,8]$ but it remains to be determined whether the alterations in energy metabolism are similar irrespective of the route of insulin administra- 
tion. Insulin has different effects on the synthesis of different hepatic proteins [9] and a link between synthetic activity, energy metabolism and insulin in the liver may be of importance. These questions cannot be answered in humans by controlled portal vs systemic studies. Therefore, the current study to elucidate the effects of pre-portal vs systemic insulin administration on protein and energy metabolism was performed in insulin-dependent diabetic dogs, maintained in a normoglycaemic state. Because of the established effects of systemic insulin administration on energy expenditure $[7,8]$, the resting metabolic rates were also investigated. The same animals served as controls when they were in an insulin-deprived, hyperglycaemic state for metabolic rate measurements.

\section{Materials and methods}

Animals The specific aims and design of this study were approved by the Animal Ethics Committee of the Ministry of Nutrition, Agriculture, Forests and Fisheries of Mecklenburg-Vorpommern, Schwerin, Germany (Reg. No: VI462a 7221/3-TV-026/91). Animals were obtained from Versuchstierzucht Groß-Börnecke, D-39435 GroßBörnecke, Sachsen-Anhalt, Germany. Ten male, long-term experimentally diabetic ASDI dogs (the result of crossbreeding German shepherd and Australian Dingo) weighing $23 \pm 1 \mathrm{~kg}$ were studied at an age of $26 \pm 5$ months.

Diabetes was induced by subtotal pancreatectomy $(90 \%$ of estimated organ weight removed) in combination with intra-pancreatico-arterial infusion of $2 \mathrm{mg} / \mathrm{kg}$ streptozotocin, as previously reported [10]. The animal model has been proved to be canine C-peptide-negative. The stools showed no steatorrhoea. At the time of the first experiment, duration of diabetes was $5 \pm 3$ months. Daily metabolic control was achieved by means of two pelleted meals and of three subcutaneous injections of regular insulin (Actrapid HM; $40 \mathrm{IU} / \mathrm{ml}$; Novo Nordisk Pharma, Mainz, Germany; average dose $1.4 \pm 0.1 \mathrm{IU} \mathrm{kg}^{-1}$ day $^{-1}$ ), which were adjusted to avoid ketonuria and to maintain stable body weight and glycaemic excursions between 4 and $12 \mathrm{mmol} / \mathrm{l}$.

Preparation for the experimental procedure From 4 weeks before the start of the study, the dogs were regularly accustomed to free-standing in a Pavlov harness for the duration of the planned procedure. Three weeks before the start of the study, a portal venous infusion catheter $(0.040 \times 0.085$-in. silicone tubing $[0.1 \times 0.2 \mathrm{~cm}]$; Intracath, Toronto, ON, Canada) was implanted in the diabetic animals through a midline laparatomy, as previously detailed [11]. The external ends of the catheters were kept in the pocket of a canvas jacket that was worn by the animals throughout the study period. Catheters were flushed twice weekly with heparinised saline $(100 \mathrm{IU} / \mathrm{ml}$; Biochemie, Vienna, Austria). During the week before the first metabolic study, the dogs were trained three times a day to breathe through a self-manufactured mouth mask. An inflated cuff around the mask guaranteed complete passage of breath air on the route requested. Breathing under these conditions was well tolerated by all the dogs.

Experimental groups Eight out of the total of ten animals served in paired pre-portal (PI) vs systemic (SI) insulin infusion studies, and six of these acted as pre-controls for insulin withdrawal (IW). The order of the two or three, respectively, different trials in a given animal, was randomly assigned. To avoid additional surgical procedures in the same animal we did not perform liver biopsies in these dogs during insulin deprivation and therefore liver protein synthesis rates were not measured during insulin deprivation. The protein synthesis measurements only include paired studies involving two treatment approaches: preportal and systemic insulin administration.

Infusates For glucose-controlled insulin infusion (GCII), Actrapid insulin was diluted with $0.154 \mathrm{~mol} / \mathrm{l} \mathrm{NaCl}$ supplemented with $10 \% \mathrm{v} / \mathrm{v}$ homologous serum to give a final concentration of $240 \mathrm{mU} / \mathrm{ml}$.

D- $\left[6-{ }^{3} \mathrm{H}\right]$ Glucose from Amersham International (Little Chalfont, UK; specific activity $1184 \mathrm{GBq} / \mathrm{mmol}$ ), was used. The entire tracer dose to be applied in one experiment was diluted with $50 \mathrm{ml}$ saline.

Sodium $\left[1-{ }^{13} \mathrm{C}\right]$ bicarbonate (98 atm.\% excess) and $\mathrm{L}-\left[1-{ }^{13} \mathrm{C}\right]$ leucine (99 atm.\% excess) were purchased from Cambridge Isotope Laboratories (50 Frontage Road, Andover, MA, USA). The L- $\left[1-{ }^{13} \mathrm{C}\right]$ leucine dose was dissolved in $300 \mathrm{ml}$ saline.

The chemical, isotopic and optical purities of these compounds were confirmed prior to use. Solutions were prepared under sterile conditions and were shown to be free of bacteria and pyrogens before use.

Protocol One week before the metabolic studies the dogs were put on a controlled diet consisting of $350 \mathrm{~g}$ pellets (Noblesse; Paragon Petcare, Nettetal-Leuth, Germany) $+150 \mathrm{~g}$ canned dog food (BEWI DOG, Südlohn, Germany) (composition: carbohydrate $44 \%$, fat $26 \%$, protein $26 \%$ and ash 4\%), which were given twice daily (at 06:00 and 18:00 hours).

On the day before the experiment, blood glucose was maintained between 6 and $10 \mathrm{mmol} / \mathrm{l}$ by means of individually adapted s.c. insulin doses given at 06:00, 11:00 and 16:00 hours, and the dogs received their last meal at 10:00 hours.

In the PI and SI studies, the dogs were taken to the laboratory at 18:00 hours the evening before the experiment. A cannula was inserted into one cephalic vein to take blood samples for blood glucose monitoring, and an infusion catheter was inserted into one saphenous vein with its tip in the lower caval vein. Background saline infusion $(0.25 \mathrm{ml} / \mathrm{min})$ was commenced; all other infusions were connected to this line (except insulin in the PI tests) and were applied by means of separate pumps (Perfusor E; B. Braun-Melsungen, Melsungen, Germany) according to protocol (see below). GCII was also started at this time, either via the implanted portal catheter (PI) or via the saphenous catheter (SI). GCII was performed on the 
basis of plasma glucose determinations at intervals of 10 or 20 min, respectively, and subsequent adjustment of insulin infusion rate according to a modified empirical algorithm employing standard parameters as presented before [12]. Thus, normoglycaemic steady state was established and maintained throughout until 15:30 hours on the following day (i.e. the day of the experiment).

At 04:00 hours on the experimental day, the animals were allowed a 15-min walk outside the laboratory to relieve themselves. Thereafter, a central-venous catheter was inserted via an external jugular vein for additional blood samplings. At 04:30 hours respiration was monitored three times for about 7-8 min. Two one-way valves permitted the animals to inhale room air directly and to exhale via a tube into the metabolic cart (Datex Deltatrac, Metabolic Monitor; Instrumentarium Corp., Helsinki, Finland), which was run in the respiration mode. Also, for later MS analysis of $\mathrm{CO}_{2}$, breath was sampled via this breath tube into $20 \mathrm{ml}$ vacutainers.
The $\left[1-{ }^{13} \mathrm{C}\right]$ leucine tracer infusion was started at 05:00 hours. At this time (i.e. $19 \mathrm{~h}$ after the last meal), enteral absorption appeared to be completed [13], and no appreciable further change of feedback-controlled insulin infusion rate was to be expected (cf. Fig. 1). Priming doses of $\mathrm{L}-\left[1-{ }^{13} \mathrm{C}\right]$ leucine $(0.8 \mathrm{mg} / \mathrm{kg})$, and of $\left[{ }^{13} \mathrm{C}\right]$ bicarbonate $(0.2 \mathrm{mg} / \mathrm{kg})$ were given intravenously and a constant infusion of $\mathrm{L}-\left[1-{ }^{13} \mathrm{C}\right]$ leucine $\left(1 \mathrm{mg} \mathrm{kg}{ }^{-1} \mathrm{~h}^{-1}\right)$ was maintained for $10 \mathrm{~h}$ at a rate of $0.5 \mathrm{ml} / \mathrm{min}$.

A primed constant infusion of $\mathrm{D}-\left[6-{ }^{3} \mathrm{H}\right]$ glucose $(122$ $\mathrm{kBq} / \mathrm{kg}$ prime; $1,029 \mathrm{~Bq} \mathrm{~kg}{ }^{-1} \min ^{-1}$ infusion dose) was applied from 11:00 hours for $240 \mathrm{~min}$ at a rate of $0.208 \mathrm{ml} / \mathrm{min}$.

Mixed-venous blood samples were taken at 04:50, 05:00, 07:00, 08:00, 09:00, 10:00, 11:00, 12:00, 13:00, 14:00 and 15:00 hours to estimate labelled leucine, ketoisocaproate (KIC) and labelled plasma proteins, albumin and fibrinogen. Blood to analyse metabolites was taken at 05:00, 10:00 and 15:00 hours. To determine the specific

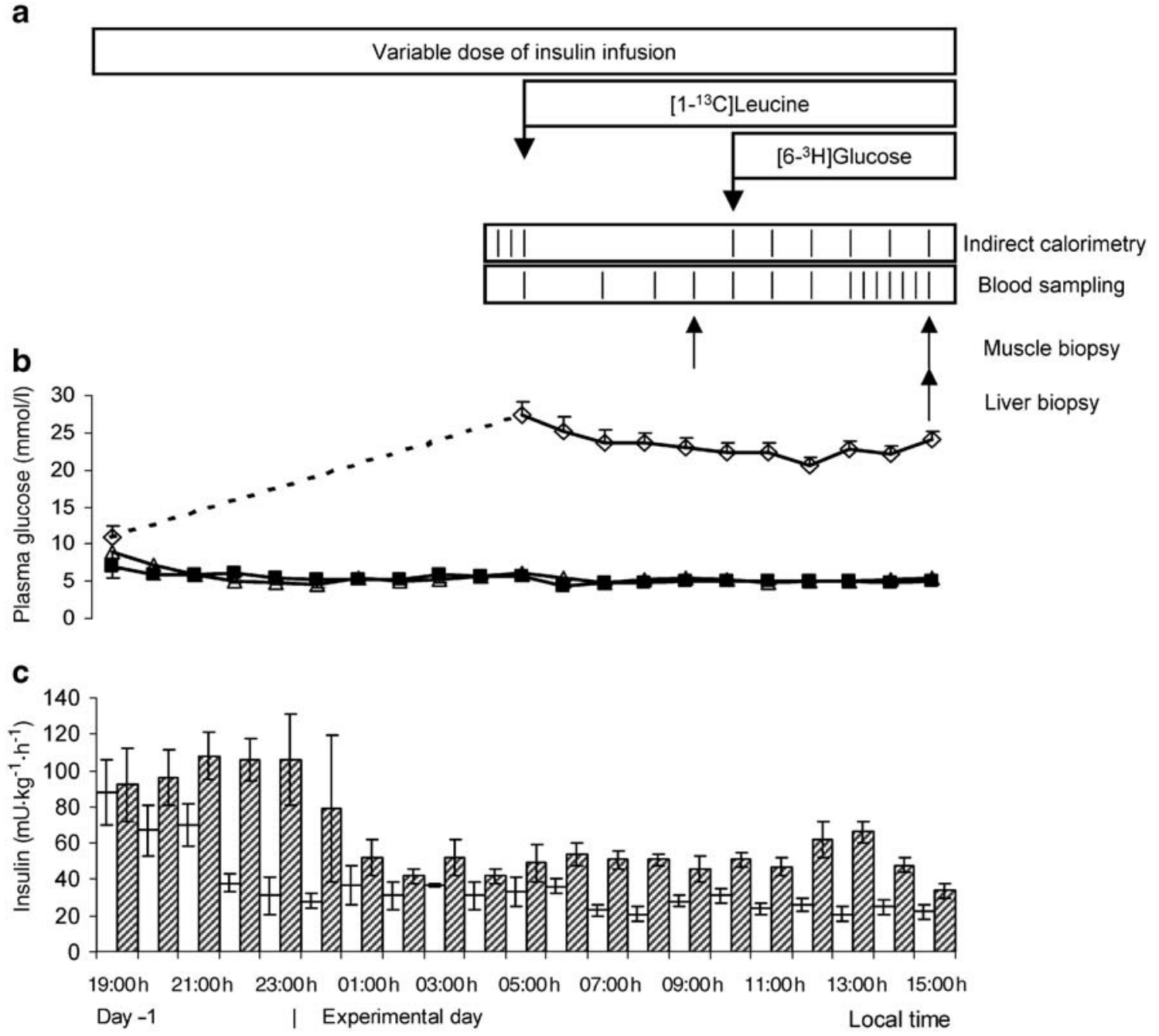

Fig. 1 Protocol design (a), plasma glucose (b) and insulin infusion rate (c). b Course of plasma glucose during SI (open triangles, $n=8$ ), PI (filled squares, $n=8$ ) and IW (open diamonds, $n=6$ ) protocols. The dotted line represents the time period during which no samples were measured. $\mathbf{c}$ Insulin dose patterns in the PI (hatched bars) and SI (open bars) protocols on the experimental day and the day before (day -1 ). Data are presented as means \pm SEM. The timing of the measurements made is indicated in a 
activity of blood glucose, additional blood samples were taken at 20-min intervals between 13:20 and 15:00 hours.

Metabolic cart data (carbon dioxide production $\left(\dot{V} \mathrm{CO}_{2}\right)$; oxygen uptake $\left(\dot{V} \mathrm{O}_{2}\right)$, breath volume $(V)$, energy expenditure in $\mathrm{kcal} / 24 \mathrm{~h}$ ) were monitored at 1 -h intervals between 10:00 and 15:00 hours. Blood gases were analysed from central venous blood at 12:00 hours, immediately after the related metabolic cart monitoring, using the AVL 990S Automatic Blood Gas System (Graz, Austria).

At 09:00 hours a muscle biopsy was taken from the vastus lateralis muscle under local anaesthesia $(0.8 \mathrm{ml}$ lidocaine 2\%; Braun Melsungen, Germany). At 15:00 hours, general anaesthesia was induced $(0.5 \mathrm{~g}$ Pentobarbital; United Pharmaceutical Works, Prague, Czech Republic) and additional biopsies were taken from the same muscle of the other lower leg and from the liver via median mini-laparotomy. All tissue samples were frozen immediately in liquid nitrogen.

In a given dog, sequential experiments (IW where appropriate vs PI vs SI) were performed after complete wound healing at an interval of approximately 1 month. In the respective repeats, the biopsies were taken from the same sites at an appropriate distance from the original biopsy points, except the control experiments (IW) where liver biopsies were not taken.

In the IW, SI and PI protocols, central venous $\mathrm{pH}$ was $7.31 \pm 0.01,7.35 \pm 0.01$ and $7.37 \pm 0.01$, respectively, showing the tendency of acidosis only in the insulin-deprived animals $(p<0.01) ; \mathrm{PCO}_{2}$ was $4.91 \pm 0.24,4.85 \pm 0.20$ and $4.60 \pm 0.10 \mathrm{mmHg}$, respectively, ruling out hyperventilation and no other variables of acid-base metabolism differed from those in a non-diabetic control group.

White blood cell counts on the day of the experiment did not differ between sequential trials $(10 \pm 1 \cdot[\times 109] / 1$ vs $9 \pm 1$. $[\times 109] / 1$, NS). In all animals, the haematocrit, which declined during a given experiment from $0.41 \pm 0.01$ to $0.37 \pm 0.01$, restored to the pre-experimental level during the 1-month interval between experiments.

In the control tests (IW), the dogs underwent the same procedure except that they did not receive any insulin after 14:00 hours the day before the experiment. Their plasma glucose was 11.0 $\pm 1.4 \mathrm{mmol} / \mathrm{l}$ at 19:00 hours. They were taken to the laboratory at 04:00 hours on the experimental day.

Analysis of samples Plasma concentrations of glucose were measured throughout the experiment, using established automated enzymatic techniques (Beckman Analyzer, Fullerton, CA, USA).

Plasma $\beta$-hydroxybutyrate, lactate and pyruvate were measured by standard enzymatic-spectrophotometric procedures as detailed previously $[11,14]$. The activity of tritiated glucose was measured after deproteination and lyophilisation of plasma and re-dissolution of the extracts as described previously [15]. ${ }^{13} \mathrm{C}$ enrichment in breath samples was analysed by isotopic mass spectrometry (IRMS) [16].
Plasma KIC was extracted from plasma and measured as its quinoxalinol-trimethylsilyl derivative using chemical ionisation [17]. Tissue fluid amino acids were extracted from muscle and liver tissue using perchloric acid and were analysed as their $t$-butyldimethylsilyl ester derivative [18]. Plasma and tissue fluid enrichment levels of $\left[1-{ }^{13} \mathrm{C}\right]$ leucine were determined by gas chromatography/mass spectrometry as previously described [19]. The amino acids from the plasma samples were isolated by cation exchange chromatography and dried down. All standards and samples were derivatised with $N$-methyl- $N$ ( $t$-butyldimethyl)-trifluoroactamide $+1 \% t$-butyldimethylchlorosilane in acetonitrile (Regis Technologies, Morton Grove, IL, USA) at room temperature overnight. The derivatives were injected onto a $30 \mathrm{~m} \times 0.25 \mathrm{~mm} \times 0.25 \mu \mathrm{m}$ film DB5MS column ( $\mathrm{J}$ and W Chromatography, Folsom, CA, USA) in a gas chromatograph oven at constant flow of helium $(1.1 \mathrm{ml} / \mathrm{min})$. The injector temperature was $250^{\circ} \mathrm{C}$. The column was heated with a gradient programme as follows: $120^{\circ} \mathrm{C}$ for $1 \mathrm{~min}$; increase to $210^{\circ} \mathrm{C}$ at $25^{\circ} \mathrm{C} / \mathrm{min}$, to $225^{\circ} \mathrm{C}$ at $25^{\circ} \mathrm{C} / \mathrm{min}$, to $265^{\circ}$ at $10^{\circ} \mathrm{C} / \mathrm{min}$, to $300^{\circ} \mathrm{C}$ at $25^{\circ} \mathrm{C} / \mathrm{min}$ and finally to $325^{\circ} \mathrm{C}$ at $10^{\circ} \mathrm{C} / \mathrm{min}$ and held for $2 \mathrm{~min}$. Under electron ionisation, ion mass was monitored at $\mathrm{m} / \mathrm{z} 200$, 201, 302, 303 and 304 for leucine using a Hewlett Packard 5,972 MSD (Hewlett Packard, Avondale, CA, USA) [20].

Mixed liver tissue proteins and muscle proteins were analysed by gas chromatography/combustion/isotopic mass spectrometry after acid precipitation and hydrolysis as reported elsewhere [16]. The hydrolysed muscle and liver proteins were derivatised as their $N$-heptafluorobutyrylmethyl esters. The amino acids were separated in a DB5MS $0.5-\mu \mathrm{m}$ film fused silica column and oven temperature was set as previously described [16]. Helium was used as the carrier gas. The mass spectrometry analysis and the calculation of atom per cent excess was performed as previously described [16]. Plasma albumin and fibrinogen were isolated and purified, and their isotopic enrichment was measured as previously described [21].

To determine serum amino acid concentrations, samples were deproteinised by means of $80 \mathrm{mmol} / \mathrm{l}$ sulphosalicylic acid. After supplementation with $25 \mu \mathrm{mol} / \mathrm{l}$ norleucine as an internal standard and centrifugation, $40 \mu \mathrm{l}$ of the supernatant was applied to the amino acid analyser LKB 4151 Alpha Plus (Pharmacia, Stockholm, Sweden). Analytical quality was regularly proven by means of calibration against artificial amino acid mixtures (accuracy $\geq 90 \%$, $\left.C_{\mathrm{v}} \leq 5 \%\right)$.

NEFAs were analysed using the Wako kit (NEFA C; Wako Pure Chemical Industries, Osaka, Japan) which utilises the acylation of coenzyme-A.

Radioimmunoassays of plasma insulin and pancreatic glucagon have been described elsewhere [11].

Calculations The specific activity data obtained between 500 and $600 \mathrm{~min}$ according to the experimental protocol (13:20 to 15:00 hours) were used to calculate the flux rates of glucose according to Steele's equation [22]. The means \pm SEM of the average flux rates during these five 20-min intervals are presented. 
Indirect calorimetry $\left(\dot{V} \mathrm{CO}_{2}, \dot{V} \mathrm{O}_{2}, V\right.$, energy expenditure) and calculated RQ were measured at intervals of $1 \mathrm{~h}$ between 10:00 and 15:00 hours [2,23]. The means \pm SEM of the averages of these six sets of data are presented.

Mean values of isotopic enrichment at the plateau (values from 12:00 to 15:00 hours minus basal measurements at 04:50 and 05:00 hours) were used for all calculations of amino acid kinetics. Plateau values of isotopic enrichment of leucine and KIC, respectively, were verified from the zero slope of a time-dependent plot between 12:00 and 15:00 hours. Equations used for calculation of leucine kinetics are discussed elsewhere [24, 25].

The fractional synthesis rate (FSR) of mixed muscle protein was calculated from the increment in $\left[1-{ }^{13} \mathrm{C}\right]$ leucine enrichment of mixed muscle protein between the two muscle biopsies, using leucyl-tRNA enrichment as the precursor pool $[18,19,26]$. A similar approach was used for the calculation of FSR of liver tissue protein [23]. The FSRs of albumin and fibrinogen were calculated from the slopes of isotopic enrichment of albumin and fibrinogen as previously reported [21]. Since in a previous study [23] we have found plasma $\left[{ }^{13} \mathrm{C}\right] \mathrm{KIC}$ to mirror liver tissue tRNA ${ }^{13} \mathrm{C}$-enrichment, plasma $\left[{ }^{13} \mathrm{C}\right] \mathrm{KIC}$ was employed as the precursor pool for these calculations.

Statistical analysis The means \pm SEM of measured values or of averages over indicated intervals are presented. Paired Student's $t$ test was used to assess the significance of differences at the $p<0.05$ level in SI vs PI experiments. For comparison of these experiments with the control tests on IW, a non-paired $t$ test was applied. The SPSS Program, version 3.1 (SPSS, Chicago, IL, USA) was employed.

\section{Results}

Glucose metabolism, insulin and glucagon

Plasma glucose concentrations and GCII rates administered in the SI and PI experiments are shown in Fig. 1. At the beginning of GCII at 19:00 hours the evening before the experiments $(3 \mathrm{~h}$ after the last subcutaneous insulin administration), the animals were moderately hyperglycaemic (7-9 mmol/l). Near-normoglycaemia was reached via either route within $4 \mathrm{~h}$ of GCII and was maintained for the following $16 \mathrm{~h}$. The steady-state glycaemia levels did not differ between the PI and SI protocols $(5.1 \pm 0.3$ vs $5.5 \pm 0.3 \mathrm{mmol} / \mathrm{l}$; NS). To maintain these levels, approximately twice the insulin dose had to be applied via the preportal route (PI $54 \pm 4$ vs SI $27 \pm 2 \mathrm{mU} \mathrm{kg}^{-1} \mathrm{~h}^{-1} ; p<0.01$ ) which, however, resulted in slightly but significantly lower average plasma insulin levels than SI (Fig. $2 ; p<0.05$ ).

In contrast, in the control group withdrawn from insulin (IW), the plasma insulin levels were generally close to the detection limit of the assay [11] and thus significantly lower than in the GCII trials (Fig. 2). Accordingly, starting with similar plasma glucose levels the afternoon before, these animals were hyperglycaemic throughout the experi- a

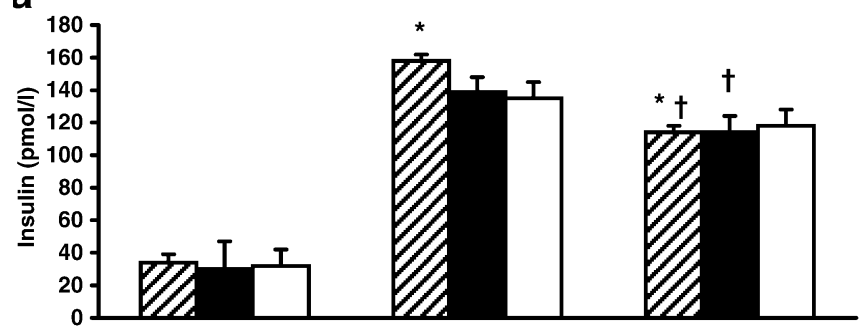

b

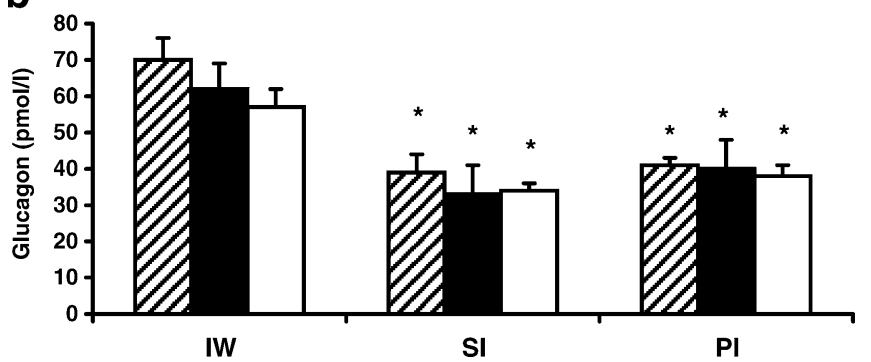

Fig. 2 Plasma insulin (a) and pancreatic glucagon levels (b) in the three experimental groups. Data are presented as means \pm SEM. Hatched bars, 0 min (05:00 hours); filled bars, $300 \mathrm{~min}$ (10:00 hours); open bars, $600 \mathrm{~min}\left(15: 00\right.$ hours). ${ }^{*} p<0.001 \mathrm{PI}$ and SI vs IW; ${ }^{\dagger} p<0.05$ PI vs SI. See also Fig. 1

mental day (05:00 hours: $27.3 \pm 1.8 \mathrm{mmol} / 1 ; p<0.001$ vs SI and PI, cf. Fig. 1).

Endogenous glucose production (Ra-glucose) was significantly lower in insulin-infused dogs (SI and PI) and the metabolic clearance rates (MCR) were higher than in the insulin-deprived animals (IW, $p<0.01$ ). Again, there was no appreciable difference between the SI and PI protocols (Table 1).

Plasma glucagon levels were consistently lower in dogs receiving insulin compared to those on the IW protocol $(p<0.05)$ with no appreciable difference between PI and SI (Fig. 2).

\section{Substrate concentrations}

The diabetic dogs receiving insulin (PI and SI) had consistently lower plasma levels of NEFA, glycerol, and $\beta$-hydroxybutyrate than the insulin-deprived dogs $(p<0.05)$

Table 1 Average plasma glucose concentration, rate of endogenous appearance (Ra-glucose) and metabolic clearance rate (MCR) of glucose in the three experimental protocols

\begin{tabular}{llrr}
\hline Variable & IW & \multicolumn{1}{l}{ SI } & \multicolumn{1}{l}{ PI } \\
\hline Plasma glucose $(\mathrm{mmol} / 1)$ & $22.78 \pm 1.10^{* *}$ & $5.27 \pm 0.12$ & $4.93 \pm 0.21$ \\
Ra-glucose & $58.28 \pm 9.30^{* * *}$ & $18.59 \pm 1.62$ & $18.18 \pm 0.97$ \\
$\quad\left(\mu \mathrm{mol} \mathrm{kg} \mathrm{min}^{-1}\right)$ & & & \\
$\begin{array}{l}\text { Rd-glucose } \\
\left(\mu \mathrm{mol} \mathrm{kg} \mathrm{min}^{-1}\right)\end{array}$ & $57.97 \pm 9.32 * *$ & $18.94 \pm 1.62$ & $18.74 \pm 0.85$ \\
\hline
\end{tabular}

Average of six measurements $20 \mathrm{~min}$ apart

$* p<0.01$ vs SI and PI 
Table 2 Plasma concentrations of substrates in the three experimental groups

\begin{tabular}{lccc}
\hline Measurements & IW & SI & PI \\
\hline NEFAs $(\mu \mathrm{mol} / 1)$ & $2,299 \pm 165$ & $954 \pm 89^{*}$ & $840 \pm 103^{*}$ \\
Glycerol $(\mu \mathrm{mol} / 1)$ & $2,395 \pm 232$ & $1,052 \pm 140^{*}$ & $840 \pm 160^{*}$ \\
$\beta$-hydroxybutyrate $(\mu \mathrm{mol} / 1)$ & $244 \pm 34$ & $103 \pm 17^{*}$ & $74 \pm 20^{*}$ \\
Lactate $(\mu \mathrm{mol} / \mathrm{l})$ & $760 \pm 140$ & $670 \pm 125$ & $726 \pm 92$ \\
Pyruvate $(\mu \mathrm{mol} / \mathrm{l})$ & $49 \pm 8$ & $79 \pm 12$ & $78 \pm 17$ \\
\hline
\end{tabular}

The data are presented as the means \pm SEM of measurements at 05:00 hours $(0 \mathrm{~min}), 10: 00$ hours $(300 \mathrm{~min})$ and 15:00 hours $(600 \mathrm{~min})$ $* p<0.05$ vs IW

but the concentrations were not influenced by the route of insulin infusion. Lactate and pyruvate did not differ between the experimental groups (Table 2).

Plasma amino acids

Comparing the prehepatic with the posthepatic route of insulin administration in the GCII protocols, the only remarkable difference was that the alanine levels were higher in PI than in SI $(p<0.05)$.

In the IW group, plasma levels of Asp, Glu, Val, Ile, Leu, Orn and Lys tended to be higher, but those of Ser, Asn, Gln, Gly, Ala and Arg tended to be lower than in the two groups on GCII (SI and PI). However, only part of these differences reached the level of statistical significance (Table 3).

Table 3 Plasma amino acid levels $(\mu \mathrm{mol} / \mathrm{l})$ in the three experimental protocols of diabetic dogs

\begin{tabular}{lccc}
\hline Amino acid & IW & SI & PI \\
\hline Asp & $8.8 \pm 1.0$ & $6.5 \pm 0.5$ & $7.6 \pm 0.5$ \\
Thr & $172.9 \pm 16.7$ & $168.9 \pm 16.5$ & $156.8 \pm 13.6$ \\
Ser & $111.4 \pm 12.8$ & $154.1 \pm 9.7^{*}$ & $133.2 \pm 8.7$ \\
Asn & $98.2 \pm 11.2$ & $123.5 \pm 7.7$ & $111.5 \pm 6.0$ \\
Glu & $44.2 \pm 5.7$ & $36.5 \pm 2.4$ & $33.8 \pm 2.5$ \\
Gln & $698.7 \pm 79.9$ & $970.8 \pm 32.1^{*}$ & $963.7 \pm 34.2^{*}$ \\
Gly & $126.9 \pm 13.4$ & $185.4 \pm 11.4^{*}$ & $170.8 \pm 10.4^{*}$ \\
Ala & $201.2 \pm 42.0$ & $285.6 \pm 54.2$ & $417.6 \pm 71.6 \#$ \\
Val & $447.5 \pm 49.1$ & $181.8 \pm 11.4^{*}$ & $169.7 \pm 5.7^{*}$ \\
Met & $39.3 \pm 4.1$ & $37.3 \pm 2.2$ & $37.9 \pm 3.5$ \\
Ile & $221.4 \pm 25.7$ & $65.9 \pm 3.7^{*}$ & $64.0 \pm 2.6^{*}$ \\
Leu & $374.1 \pm 41.6$ & $162.5 \pm 10.5^{*}$ & $148.9 \pm 5.2^{*}$ \\
Tyr & $43.6 \pm 4.9$ & $39.9 \pm 3.6$ & $40.9 \pm 1.8$ \\
Phe & $67.1 \pm 6.5$ & $58.2 \pm 3.8$ & $65.3 \pm 2.8$ \\
Orn & $24.1 \pm 2.7$ & $18.6 \pm 1.1$ & $19.8 \pm 1.4$ \\
Lys & $205.8 \pm 21.6$ & $188.2 \pm 14.3$ & $181.5 \pm 9.2$ \\
His & $72.8 \pm 7.7$ & $64.9 \pm 4.0$ & $69.5 \pm 2.5$ \\
Arg & $84.8 \pm 8.9$ & $129.4 \pm 10.2^{*}$ & $118.4 \pm 8.6^{*}$ \\
\hline
\end{tabular}

Data are presented as the means \pm SEM of sampling at 10:00 and

15:00 hours

${ }^{*} p<0.05$ vs IW

$\# p<0.05$ vs SI
Table 4 Whole-body leucine kinetics and mixed muscle protein synthesis in the three experimental groups

\begin{tabular}{lccc}
\hline Measurements & IW & SI & PI \\
\hline $\begin{array}{l}\text { Leucine flux } \\
\left(\mu \mathrm{mol} \mathrm{kg} \mathrm{k}^{-1} \mathrm{~h}^{-1}\right)\end{array}$ & $283 \pm 15$ & $243 \pm 6^{*}$ & $262 \pm 10$ \\
$\begin{array}{c}\text { Leucine oxidation } \\
\left(\mu \mathrm{mol} \mathrm{kg} \mathrm{k}^{-1}\right)\end{array}$ & $80 \pm 12$ & $36 \pm 4^{*}$ & $54 \pm 5^{* \#}$ \\
$\begin{array}{c}\text { Non-oxidative leucine } \\
\text { disappearance rate } \\
\left(\mu \mathrm{mol} \mathrm{kg} \mathrm{h}^{-1}\right)\end{array}$ & $203 \pm 12$ & $206 \pm 8$ & $207 \pm 9$ \\
$\begin{array}{c}\text { FSR of mixed muscle } \\
\text { proteins }(\% / \mathrm{h})\end{array}$ & $0.050 \pm 0.003$ & $0.059 \pm 0.008$ & $0.052 \pm 0.012$ \\
\hline
\end{tabular}

The data are presented as means \pm SEM. Leucine flux indicates overall protein breakdown, leucine oxidation represents irreversible loss of protein, and non-oxidative leucine disappearance rate indicates leucine disposal via protein synthesis $* p<0.05$ vs IW $\# p<0.05$ vs SI

Whole-body leucine metabolism and FSRs of proteins

In the well-insulinised, normoglycaemic state during GCII, PI led to slightly higher rates of leucine flux and oxidation than SI and to slightly lower mixed muscle protein FSR (Table 4). The FSR of liver tissue proteins, albumin and fibrinogen, however, were significantly higher during preportal insulin administration (Fig. 3). Thus, there was no related difference in the overall non-oxidative leucine disappearance rate (NOLD, Table 4). As shown above (cf. Table 3), no significant difference could be assessed in the plasma leucine levels either.

On insulin withdrawal (IW), however, the elevated plasma leucine levels were paralleled by significant elevations in the rates of leucine flux and oxidation but not of NOLD, and - under these conditions - mixed muscle protein synthesis appeared only marginally reduced (Table 4).

\section{Indirect calorimetry}

PI administration resulted in significantly higher energy expenditure than SI. The RQ was also significantly higher following PI than during SI administration $(p<0.05) . \dot{V} \mathrm{O}_{2}$,

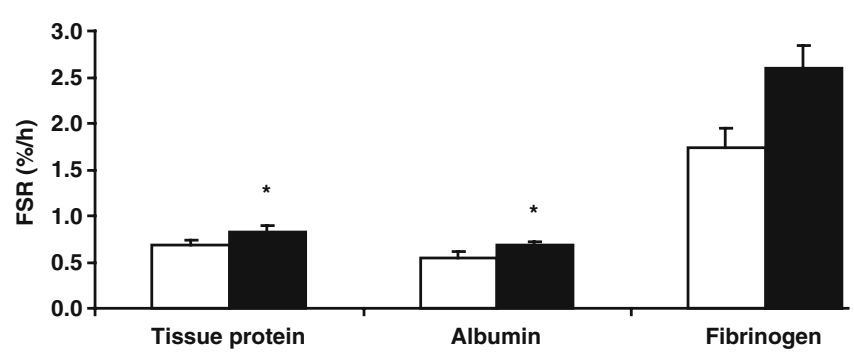

Fig. 3 FSRs of liver tissue protein, albumin and fibrinogen in the SI and PI protocols. Data are presented as means \pm SEM. Open bars, SI; filled bars, PI. ${ }^{*} p<0.001$ PI and SI vs IW 

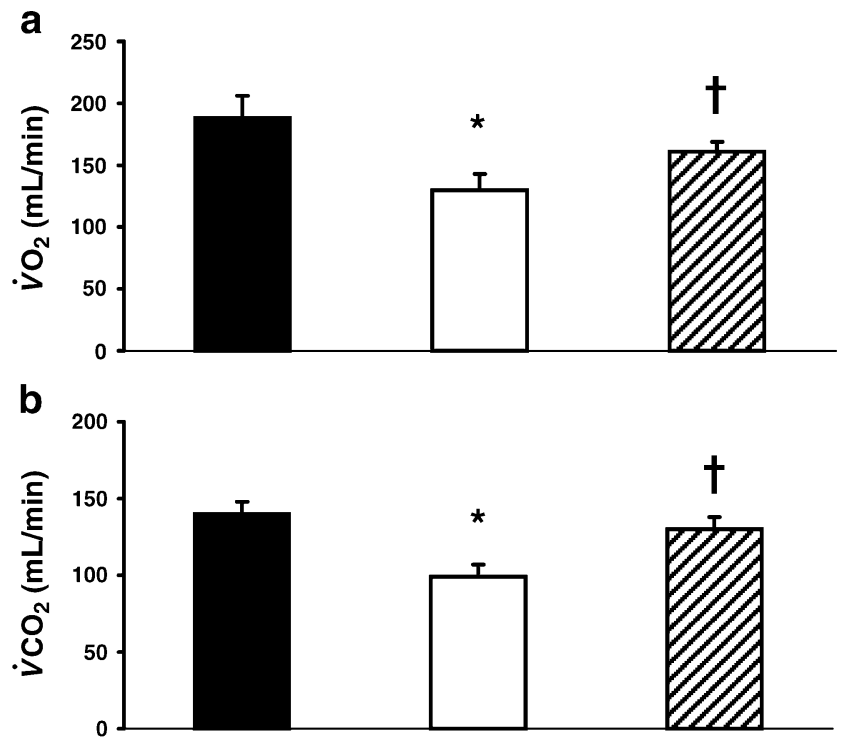

C
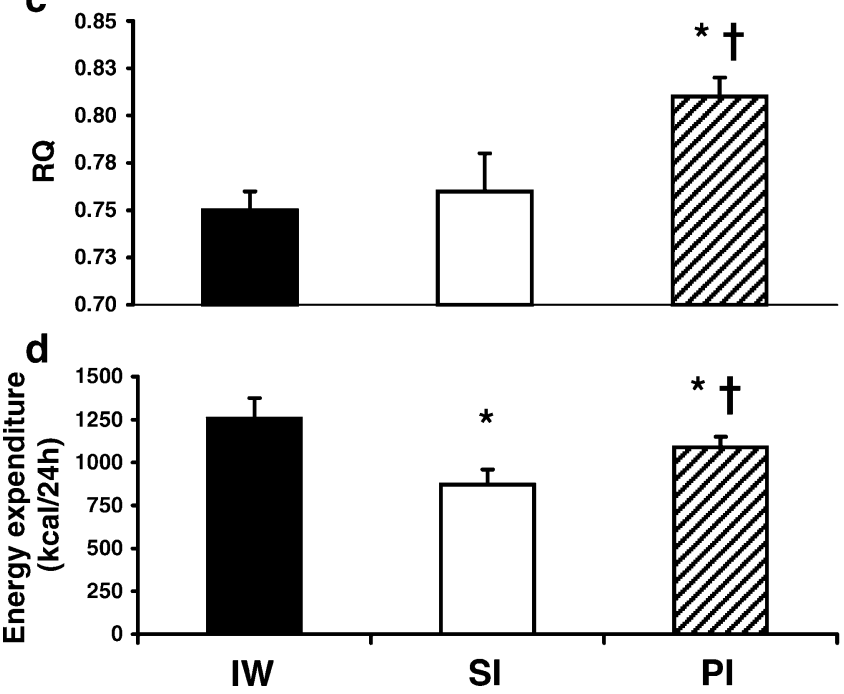

Fig. 4 Indirect calorimetry data (oxygen consumption $\left[\dot{\mathrm{V}} \mathrm{O}_{2}\right]$, carbon dioxide $\left[\dot{V} \mathrm{CO}_{2}\right]$, RQ and energy expenditure) in the three experimental groups. The data are the mean $\pm \mathrm{SEM}$ of six measurements made $1 \mathrm{~h}$ apart. ${ }^{*} p<0.001 \mathrm{PI}$ and SI vs IW; ${ }^{\dagger} p<0.05$ PI vs $\mathrm{S}$

$\dot{V} \mathrm{CO}_{2}$ and energy expenditure were lower in PI and SI than in IW $(p<0.05)$. In contrast, RQ were similar during IW and SI $(p>1.0)$ (Fig 4).

\section{Discussion}

It was previously reported that insulin-dependent, ketosisprone diabetic dogs [11] are characterised by enhanced appearance rate but reduced metabolic clearance rate of glucose. These animals also demonstrated increased leucine flux but reduced RQ. In the current study we further investigated the effect of different routes of insulin administration (pre-portal vs systemic) on energy metabolism and synthesis rates of muscle and liver proteins. To main- tain similar blood glucose and glucose kinetics, the insulin requirement was higher when insulin was administered pre-portally. Systemic insulin administration caused a reduction in the synthesis rate of liver proteins (albumin and fibrinogen as well as tissue proteins). It also resulted in lower energy expenditure, leucine oxidation and RQ. Of note, the RQ were similar when insulin was withdrawn and when it was administered systemically. Therefore, systemic insulin administration caused greater reduction in leucine oxidation and energy expenditure than when insulin was administered pre-portally.

The results from this animal study cannot be directly translated to the clinical situation in patients with type 1 diabetes. However, the differences in energy metabolism demonstrated in the current animal experiments have many potential clinical implications. Firstly, the pre-portal administration caused an increase in RQ unlike systemic insulin administration, indicating higher carbohydrate oxidation. As has been previously reported in people with type 1 diabetes [7,8], insulin withdrawal caused an increased energy expenditure and insulin administration resulted in reduction of energy expenditure. However, the current study demonstrated that the route of administration has a significant effect on the magnitude of fall in energy expenditure. The systemic administration of insulin caused an approximately $30 \%$ reduction in energy expenditure whereas pre-portal administration caused only a $13 \%$ reduction in energy expenditure. In paired analysis the systemic administration, as opposed to pre-portal administration, was associated with an average $20 \%$ lower energy expenditure (average $219 \mathrm{kcal} /$ day) which can theoretically result in $0.7 \mathrm{~kg}$ fat accretion per month. However, the current study was performed in the fasted state while the post-prandial state represents the greater part of the day. It is possible that the response of the energy metabolism to different routes of insulin administration may differ between the fasted and the fed state. Post-prandial changes in energy metabolism, however, are a smaller component than the resting energy expenditure [27]. We further propose that the results from the current animal study suggests that in human diabetic patients the current method of administering insulin via a peripheral route has the potential to cause weight gain as observed during intensive insulin treatment [3].

The cause of this substantially lower energy expenditure following systemic insulin administration is not entirely clear from the current study. A previous human study indicated that glucagon has thermogenic effect in humans [28] and increased glucagon levels following insulin-deprivation is mostly responsible for increased energy expenditure in type 1 diabetic patients during insulin deprivation [8]. Plasma glucagon levels substantially decreased during both systemic (average 47\%) and pre-portal insulin administration (average 35\%). The reduction in glucagon is likely to have contributed to the fall in energy expenditure, but it is not clear whether in systemic vs pre-portal administration the differences in energy expenditure can be explained on the basis of the different magnitudes in the fall of glucagon levels. The relative concentrations of glucagon 
and insulin are reported to have important metabolic consequences [29]. The relative increase in insulin concentration in the liver during pre-portal insulin administration may increase leucine oxidation. Our previous studies demonstrated that decarboxylation of ketoisocaproate is enhanced by insulin [20]. Increased insulin in the liver can also potentially enhance many other energetically costly processes as shown in the case of protein synthesis. Reduction in gluconeogenesis, an energy consuming biochemical process that increases during insulin deficiency, is proposed as a cause of insulin-induced fall in energy expenditure [30]. However, in the current study there is no evidence to suggest a lesser reduction in gluconeogenesis following pre-portal insulin administration. On the contrary, the higher circulating alanine following pre-portal insulin delivery found in this investigation and also reported previously from our laboratory [11], even after peritoneal administration of insulin [31], suggests that gluconeogenesis was lower because less alanine was consumed for gluconeogenesis. Another potential reason is that leucine flux, which represents protein turnover [25], was significantly reduced by systemic insulin treatment whereas no significant change was noted with pre-portal insulin administration. We also noted that pre-portal insulin administration resulted in higher RQ, indicating increased oxidation of carbohydrates as a fuel.

Previous studies have demonstrated that whole-body protein turnover (leucine flux) accounts for approximately $25 \%$ of resting metabolic rate [32]. A greater reduction of leucine flux, thus may be an independent factor for the reduction in energy expenditure following systemic insulin infusion. Leucine oxidation was also reduced to a greater extent during systemic insulin infusion, which might also have contributed to the lower energy expenditure found in diabetic dogs during systemic insulin administration. Amino acid catabolism results in ammonia formation and then, through the ornithine cycle, in urea production, which is an energy-consuming reaction. The greater reduction in leucine oxidation also may have contributed to the lower energy expenditure in diabetic dogs during systemic insulin administration. The increased synthesis rates of liver tissue proteins and albumin occurring with pre-portal insulin administration may have contributed to higher energy expenditure because protein synthesis is an energy-consuming reaction.

It is intriguing that systemic insulin administration resulted in a greater reduction in leucine flux, a measure of whole-body protein turnover. The main difference between the delivery of insulin via the systemic and pre-portal routes is that the former is associated with an estimated $50 \%$ decrease in insulin levels in hepatic circulation. In contrast the insulin levels are lower in hepatic circulation during systemic insulin delivery because of a $13 \pm 2 \%$ mesenteric extraction [33]. Based on regional studies it is clear that amino acids, rather than insulin, are the key regulator of splanchnic protein breakdown [34]. In con- trast, insulin is a key regulator of muscle protein turnover $[35,36]$. It is therefore likely that during systemic delivery the relatively higher steady-state systemic levels of insulin have caused suppression of muscle protein breakdown. A reduced breakdown of proteins in the peripheral tissues may reduce the ability to repair tissues. It remains to be determined whether such changes have any impact on chronic complications, especially involving microvascular complications.

We anticipated that the main differences in protein metabolism would be in the liver. The higher hepatic to systemic insulin ratio with higher hepatic liver insulin levels during pre-portal administration of insulin has pronounced effects on the synthesis of liver proteins. A higher synthesis both of tissue proteins and of export proteins in the liver was noted in this study during pre-portal vs systemic insulin administration. Previous studies where we infused insulin peripherally had no effect on liver tissue protein or albumin synthesis in a pig model [23] and nor was splanchnic protein synthesis elevated. This lack of stimulation of liver protein synthesis by systemic insulin administration suggests a relation to the simultaneous increase in peripheral and hepatic insulin levels as noted in the previous study [23]. In contrast, when in the current study insulin was delivered pre-portally resulting in relatively lower peripheral insulin levels there was a stimulation of synthesis of liver proteins. These results suggest that systemic insulin administration may alter the normal physiology of liver protein synthesis. Since most liver-derived proteins have profound systemic effects the potential impact of our study requires careful follow-up. The recent advances in proteomic approaches [37] may allow us to determine whether glycaemic control in patients with type 1 diabetes with systemic insulin administration alters the synthesis of any liver-derived plasma proteins.

We conclude that substantial differences in energy and protein metabolism occur in diabetic dogs when insulin is administered to achieve a similar glycaemic control via the systemic and pre-portal routes. Pre-portal insulin administration is associated with a smaller fall in energy expenditure. RQ is increased only by pre-portal insulin and not by systemic insulin administration, indicating a greater carbohydrate oxidation with pre-portal insulin delivery. In the long term, these changes may result in less weight gain than when insulin is administered systemically. Higher leucine flux, leucine oxidation and synthesis of liver proteins may be responsible for higher energy expenditure during pre-portal insulin administration in dogs. It remains to be determined whether the effect of systemic vs preportal insulin administration on liver protein synthesis is global or selective for certain proteins. Since many proteins originating from the liver have major functional impacts in dealing with defence against infection or stress reaction and inflammatory responses, etc., the pre-portal insulin administration of insulin may offer advantages. 
Acknowledgements This study was made possible by a grant from the Special Promotion of Scientific Cooperation programme (Sonderförderung für die Wissenschaftliche Kooperation) of the Alexander von Humboldt Foundation, Bonn, Germany (Protein metabolism in diabetes; reg. DEU/1007356), which was given to one of the authors (U. Fischer). We thank the precision engineers of the Institute of Physiology of the Ernst-Moritz-Arndt-University of Greifswald, Germany for manufacturing the breathing mask. This study was also supported by the National Institutes of Health (grants R01DK41973 and RR00585).

\section{References}

1. The Diabetes Control and Complications Trial Research Group (1993) The effect of intensive treatment of diabetes on the development and progression of long-term complications in insulindependent diabetes mellitus. N Engl J Med 329:977-986

2. Reichard P, Nilsson BY, Rosenqvist U (1993) The effect of long-term intensified insulin treatment on the development of microvascular complications of diabetes mellitus. N Engl J Med 329:304-309

3. Carlson MG, Campbell PJ (1993) Intensive insulin therapy and weight gain in IDDM. Diabetes 42:1700-1707

4. The DCCT Research Group (1988) Weight gain associated with intensive therapy in the diabetes control and complications trial. Diabetes Care 11:567-573

5. Bolli GB (1999) How to ameliorate the problem of hypoglycaemia in intensive as well as nonintensive treatment of type 1 diabetes. Diabetes Care 22:B43-B52

6. Shah P, Vella A, Basu A et al (2002) Effects of free fatty acids and glycerol on splanchnic glucose metabolism and insulin extraction in nondiabetic humans. Diabetes 51:301-310

7. Nair KS, Halliday D, Garrow JS (1984) Increased energy expenditure in poorly controlled type I (insulin-dependent) diabetic patients. Diabetologia 27:13-16

8. Charlton MR, Nair KS (1998) Role of hyperglucagonemia in catabolism associated with type 1 diabetes. Effects on leucine metabolism and the resting metabolic rate. Diabetes 47:17481756

9. De Feo P, Volpi E, Lucidi P et al (1993) Physiological increments in plasma insulin concentrations have selective and different effects on synthesis of hepatic proteins in normal humans. Diabetes 42:995-1002

10. Freyse EJ, Hahn von Dorsche H, Fischer U (1982) Low dose streptozotocin diabetes after partial pancreatectomy in dogs. Histological findings in a new type of experimental diabetes. Acta Biol Med Ger 41:1203-1210

11. Freyse EJ, Fischer U, Albrecht G, Marx S, Keilacker H (1987): The effect of prehepatic insulin administration on alanine flux rates in diabetic dogs. Diabetologia 30:402-408

12. Fischer U, Detschew W, Jutzi E et al (1985) In vivo comparison of different algorithms for the artificial beta-cell. Artif Organs 9:173-179

13. Fischer U, Freyse EJ, Albrecht G et al (1985) Daily glucose and insulin rhythms in diabetic dogs on the artificial beta cell. Exp Clin Endocrinol 85:27-37

14. Freyse EJ, Fischer U, Albrecht G, Salzsieder E (1985) Alterations in alanine metabolism in diabetic dogs during short-term treatment with an artificial B cell. Diabetologia 28:763-768

15. Freyse EJ, Fischer U, Albrecht G (1983) Glucose metabolism studied isotopically in diabetic dogs: effect of restoration of peripheral normoinsulinaemia by the artificial cell. Diabetologia 25:411-417

16. Balagopal P, Ford GC, Ebenstein DB, Nadeau DA, Nair KS (1996) Mass spectrometric methods for determination of $\left[{ }^{13} \mathrm{C}\right]$ leucine enrichment in human muscle protein. Anal Biochem 239:77-85
17. Ford GC, Cheng KN, Halliday D (1985) Analysis of [1-C-13] leucine and [C-13]KIC in plasma by capillary gas chromatography/mass spectrometry in protein turnover studies. Biomed Mass Spectrom 12:432-436

18. Baumann PQ, Stirewalt WS, O'Rourke BD, Howard D, Nair KS (1994) Precursor pools of protein synthesis: a stable isotope study in a swine model. Am J Physiol Endocrinol Metab 267: E203

19. Ljungqvist O, Persson M, Ford GC, Nair KS (1997) Functional heterogeneity of leucine pools in human skeletal muscle. Am J Physiol Endocrinol Metab 273:E564-E570

20. Nair KS, Ford GC, Ekberg K, Fernqvist-Forbes E, Wahren J (1995) Protein dynamics in whole body and in splanchnic and leg tissues in type I diabetic patients. J Clin Invest 95:2926-2937

21. Fu A, Morris JC, Ford GC, Nair KS (1996) Sequential purification of human apolipoprotein B-100, albumin, and fibrinogen by immunoaffinity chromatography for measurement of protein synthesis. Anal Biochem 247:228-236

22. Steele R (1959) Influence of glucose loading and of injected insulin on hepatic glucose output. Ann NY Acad Sci 82:420-431

23. Ahlman B, Charlton M, Fu A, Berg C, O’Brien PC, Nair KS (2001) Insulin's effect on synthesis rates of liver proteins: a swine model comparing various precursors of protein synthesis. Diabetes 50:947-954

24. Nair KS (1997) Assessment of protein metabolism in diabetes. In: Draznin B, Rizza RA (eds) Clinical research in diabetes and obesity. Part I. Methods, assessment and metabolic regulation. Humana Press, Totowa, NJ, pp 137-170

25. Matthews DE, Motil KJ, Rohrbaugh DK, Burke JF, Young R, Bier DM (1980) Measurement of leucine metabolism in man from a primed, continuous infusion of L-[1-C-13]leucine. Am J Physiol 238:E473-E479

26. Nair KS, Halliday D, Griggs RC (1988) Leucine incorporation into mixed skeletal muscle protein in humans. Am J Physiol Endocrinol Metab 254:E208-E213

27. Nair KS, Halliday D, Garrow JS (1983) Thermic response to isoenergetic protein, carbohydrate or fat meals in lean and obese subjects. Clin Sci 65:307-312

28. Nair KS (1987) Hyperglucagonemia increases resting metabolic rate in man during insulin deficiency. J Clin Endocrinol Metab 64:896-900

29. Starke A, Imamura T, Unger RH (1987) Relationship of glucagon suppression by insulin and somatostatin to the ambient glucose concentration. J Clin Invest 79:20-24

30. Nair KS, Halliday D (1985) Energy and protein metabolism in diabetes and obesity. In: Garrow JS, Halliday D (eds) Substrate and energy metabolism. John Libbey, London, pp 195-202

31. Fischer U, Fritze K, Freyse EJ (1990) Insulin therapy on the peritoneal route: effects on glucose control in experimental insulin dependent diabetes. Exp Clin Endocrinol 95:11-21

32. Welle SL, Nair KS (1990) Relationship of resting metabolic rate to body composition and protein turnover. Am J Physiol Endocrinol Metab 258:E990-E998

33. Ishida T, Chap Z, Chou J et al (1984) Effects of portal and peripheral venous insulin infusion on glucose production and utilization in depancreatized, conscious dogs. Diabetes 33:984-990

34. Nygren J, Nair KS (2003) Differential regulation of protein dynamics in splanchnic and skeletal muscle beds by insulin and amino acids in healthy human subjects. Diabetes 52:1377-1385

35. Meek SE, Persson M, Ford GC, Nair KS (1998) Differential regulation of amino acid exchange and protein dynamics across splanchnic and skeletal muscle beds by insulin in healthy human subjects. Diabetes 47:1824-1835

36. Gelfand RA, Barrett EJ (1987) Effect of physiologic hyperinsulinemia on skeletal muscle protein synthesis and breakdown in man. J Clin Invest 80:1-6

37. Nair KS, Jaleel A, Asmann W, Short KR, Raghavakaimal S (2004) Proteomic research: potential opportunities for clinical and physiological investigators. Am J Physiol Endocrinol Metab 286:E683-E874 